\title{
Test-Retest Reliability of the Patient Activation Measure-13 in Adults with Substance Use Disorders and Schizophrenia Spectrum Disorders
}

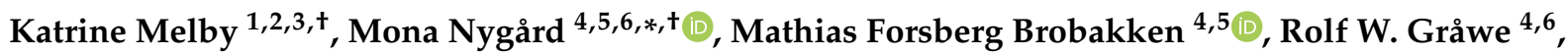 \\ Ismail Cüneyt Güzey ${ }^{4,6}$, Solveig Klæbo Reitan ${ }^{4,6}$, Einar Vedul-Kjelsås ${ }^{4,6}$, Jørn Heggelund ${ }^{7}$ \\ and Mariela Loreto Lara-Cabrera $4,6,8$ (D)
}

\section{check for} updates

Citation: Melby, K.; Nygård, M.; Brobakken, M.F.; Gråwe, R.W.; Güzey, I.C.; Reitan, S.K.; Vedul-Kjelsås, E.; Heggelund, J.; Lara-Cabrera, M.L. Test-Retest Reliability of the Patient Activation Measure-13 in Adults with Substance Use Disorders and Schizophrenia Spectrum Disorders. Int. J. Environ. Res. Public Health 2021, 18, 1185. https://doi.org/10.3390/ ijerph18031185

Academic Editor: Paul B. Tchounwou Received: 14 December 2020

Accepted: 25 January 2021

Published: 29 January 2021

Publisher's Note: MDPI stays neutral with regard to jurisdictional claims in published maps and institutional affiliations.

Copyright: (c) 2021 by the authors. Licensee MDPI, Basel, Switzerland. This article is an open access article distributed under the terms and conditions of the Creative Commons Attribution (CC BY) license (https:/ / creativecommons.org/licenses/by/ $4.0 /)$.
1 Department of Clinical and Molecular Medicine, Norwegian University of Science and Technology (NTNU), 7491 Trondheim, Norway; katrine.melby@stolav.no

2 Blue Cross Lade Addiction Treatment Centre, 7041 Trondheim, Norway

3 Department of Clinical Pharmacology, St. Olavs Hospital, Trondheim University Hospital, 7006 Trondheim, Norway

4 Department of Mental Health, Norwegian University of Science and Technology (NTNU), 7491 Trondheim, Norway; mathias.f.brobakken@ntnu.no (M.F.B.); rolf.w.grawe@stolav.no (R.W.G.); cuneyt.guzey@ntnu.no (I.C.G.); Solveig.Klebo.Reitan@stolav.no (S.K.R.); einar.vedul-kjelsas@ntnu.no (E.V.-K.); mariela.lara@ntnu.no (M.L.L.-C.)

5 Department of Østmarka, Division of Mental Health Care, St. Olavs Hospital, Trondheim University Hospital, 7006 Trondheim, Norway

6 Department of Research and Development, Division of Mental Health Care, St. Olavs Hospital, Trondheim University Hospital, 7006 Trondheim, Norway

7 Regional Center for Healthcare Improvement, St. Olavs Hospital, Trondheim University Hospital, 7006 Trondheim, Norway; jorn.heggelund@stolav.no

8 Tiller Community Mental Health Centre, Division of Psychiatry, St. Olavs Hospital, Trondheim University Hospital, 7006 Trondheim, Norway

* Correspondence: mona.nygard@ntnu.no; Tel.: +47-452-03-870

+ Equally contributed to this study and are considered shared first authorship.

Abstract: Patient Activation Measure-13 (PAM-13) is a valid and widely used questionnaire that assess an individual's knowledge, confidence, and skills for self-management of their chronic illness. Although there is some evidence regarding its reliability, the test-retest reliability has not been investigated among patients with substance use disorders (SUDs) or schizophrenia spectrum disorders. We investigated the internal consistency and test-retest reliability of PAM-13 in these populations. Test-retest reliability was analysed using data from 29 patients with SUDs and 28 with schizophrenia spectrum disorders. Cronbach's $\alpha$ and Intraclass Correlation Coefficient (ICC) scores were used to examine internal consistency and test-retest reliability, respectively. Of the 60 collected test-retest questionnaires, 57 were included in the analyses. No mean differences between time one (T1) and time two (T2) were observed in either patient group, except for item 12 in schizophrenia spectrum disorders patients $(p<0.05)$. Internal consistency for T1 and T2 was 0.75 and 0.84 in SUDs patients and 0.87 and 0.81 in schizophrenia spectrum disorders patients, respectively. The ICC was $\mathrm{r}=0.86$ in patients with SUDs and $r=0.93$ in patients with schizophrenia spectrum disorders. To conclude, PAM-13 showed good internal consistency and test-retest reliability in SUDs and schizophrenia spectrum disorders patients.

Keywords: patient activation measure-13; internal consistency; test-retest reliability; self-management; schizophrenia spectrum disorders; substance use disorder

\section{Introduction}

Substance use disorders (SUDs) and schizophrenia spectrum disorders often require long-term treatment due to early onset, long-lasting and severe symptoms [1,2]. Both patient groups commonly have relapses with detrimental effects for recovery [3-5]. Patients 
also engage in detrimental lifestyles that result in poor health status and shortened life expectancy [6]. Patient activation can be defined as the knowledge, confidence, and skills for self-management of one's health and health care. Patient activation emphasizes the patients' willingness and ability to take independent actions to manage their own health. As such, patient activation underlines the importance of understanding the patient's own role in their care process. Having knowledge about one's own treatment and knowing how to manage their condition, while remaining a functional member of society, is thus important. Accordingly, patients who have high activation levels believe they have important roles to play in self-management of their own care and tend to also have the confidence to collaborate with health-care providers [7].

Recent studies have indicated that patients with high patient activation, have better health status [8]. Other studies also suggest that patients having high activation levels have the skills and behavioural repertoire to manage their condition, even when under stress, since they know how to access to appropriate health care [7]. There is also a growing number of studies indicating that those who are more activated have better outcomes [7], and better use of health services [9]. They are more likely to adhere to treatment and take part in preventative behaviours. These positive behaviours include regular medical appointments, regular exercise, and a healthy diet. However, they are also more likely to avoid negative behaviours damaging their health, such as smoking and drug use. Additionally, they more often have prepared questions for doctor's appointments, seeking information regarding treatment options for their illness and quality of health care [7]. Therefore, it is clearly necessary to have reliable instruments to capture patient activation.

Several self-reported questionnaires have been developed to measure patient activation defined as an individual's knowledge, confidence, and skills for self-management of their chronic illness behaviour. In 2004, the 22-item Patient Activation Measure (PAM) was developed [7]. In 2005, Hibbard et al. [10] developed the 13-item version of PAM (PAM-13). The PAM-13 is the most used questionnaire developed to assess patient activation [8]. Research over the last decade has reported a positive relationship between high PAM-13 scores and better patient satisfaction and health outcomes [8]. Low PAM-13 scores were associated with higher rates of hospitalization and use of emergency room services among chronically ill patient populations $[8,9,11]$.

PAM-13 ascertains the patient's self-reported knowledge, skills and confidence in the self-management of his or her own health [10]. The questionnaire has been translated into several languages and validated for a range of mental and somatic illnesses [12-19]. PAM-13 has recently been used in studies that included patients with schizophrenia spectrum disorders [20-24], as well as patients with SUDs [25]. However, studies providing information about the test-retest reliability of the questionnaire in these settings are scarce. Test-retest reliability gives information regarding the extent to which two measurements, using the same questionnaire over a short period of time, remain the same when assessing the same unchanged individual [26]. In health research settings, the lack of test-retest reliability is an important methodological challenge, as it hinders reliable replication of results and conclusions. From clinical experience, this measurement property is also important, especially among patient groups that often are under the influence of medications and their side effects, or struggle with low confidence or poor self-esteem.

To our knowledge, six studies have investigated test-retest reliability [12-17]; of those, only one was conducted in mental health patients [14]. Although that study found PAM-13 to have good psychometric properties, mainly among outpatients with depression and anxiety disorders, the test-retest sample included neither patients with SUDs nor patients with schizophrenia spectrum disorders. People with substance use disorders and patients with schizophrenia spectrum disorders can have unstable medical conditions, and in difficult periods they can show a lack of insight into their own health situation. Reliable self-reported questionnaires, validated in clinical settings, are important to identify and plan medical treatments, according to the patient activation needs. Ensuring test reliability in these settings is therefore important, therefore, this study aims to investigate the internal 
consistency of PAM-13 and the test-retest reliability estimates for patients with SUDs and patients with schizophrenia spectrum disorders.

\section{Materials and Methods}

\subsection{Participants and Study Design}

Data was retrieved from two studies conducted in Norway between 2016 and 2018, including outpatients with SUDs and schizophrenia spectrum disorders. Patient characteristics and clinical data are presented in Table 1.

Table 1. Patient characteristics and clinical data for both patient groups.

\begin{tabular}{|c|c|c|}
\hline & $\begin{array}{l}\text { Substance Use Disorders } \\
\qquad(N=29)\end{array}$ & $\begin{array}{l}\text { Schizophrenia Spectrum } \\
\text { Disorders }(N=28)\end{array}$ \\
\hline Age, mean $(S D)$ & $46(13)$ & $34(10)$ \\
\hline Gender, male/female & $18 / 11$ & $17 / 11$ \\
\hline \multicolumn{3}{|l|}{ Primary ICD-10 Diagnosis, $n$} \\
\hline \multicolumn{3}{|l|}{ Mental and behavioural disorder due to } \\
\hline Alcohol dependence (F10.2) & 13 & - \\
\hline \multicolumn{3}{|l|}{ Use of opioids } \\
\hline Opioid dependence (F11.2) & 8 & - \\
\hline With opioid-induced mood disorder (F11.24) & 1 & - \\
\hline With opioid-induced psychotic disorder (F11.25) & 1 & - \\
\hline Cannabis use, unspecified (F12.9) & 2 & - \\
\hline Sedative, hypnotic or anxiolytic-related dependence (F13.2) & 1 & - \\
\hline \multicolumn{3}{|l|}{ Schizophrenia } \\
\hline Paranoid (F20.0) & - & 18 \\
\hline Undifferentiated (F20.3) & - & 6 \\
\hline Residual (F20.5) & - & 1 \\
\hline \multicolumn{3}{|l|}{ Schizoaffective disorder } \\
\hline Manic type (F25.0) & - & 2 \\
\hline Depressive type (25.1) & - & 1 \\
\hline Comorbid Diagnoses $(n) *$ & & 10 \\
\hline \multicolumn{3}{|l|}{ Marital status, $n$} \\
\hline Married & 8 & 2 \\
\hline Divorced & 7 & 2 \\
\hline Not married/widow/widower & 14 & 24 \\
\hline \multicolumn{3}{|l|}{ Education, $n$} \\
\hline Primary & 11 & 4 \\
\hline Secondary & 13 & 22 \\
\hline \multirow[t]{2}{*}{ Bachelor's degree or higher } & 4 & 2 \\
\hline & 1 & \\
\hline \multicolumn{3}{|l|}{ Employment status, $n$} \\
\hline Student & - & 1 \\
\hline Working & 5 & 3 \\
\hline Sick leave & 1 & - \\
\hline Rehabilitation & 11 & 8 \\
\hline Disability pension & 8 & 15 \\
\hline Retired & 1 & - \\
\hline Unemployed & 3 & - \\
\hline Working from home & - & 1 \\
\hline Other & - & - \\
\hline \multicolumn{3}{|l|}{ Living with someone, $n$} \\
\hline Alone & 18 & 15 \\
\hline Family & 11 & 4 \\
\hline With others & - & - \\
\hline Supportive housing & - & 9 \\
\hline
\end{tabular}

\footnotetext{
*Comorbid diagnoses (n): E11.9 (1), E66.8 (1), F10.1 (1), F15.2 (1), F19.2 (1), F40.1 (1), F60.9 (1), F63 (1), F84.5 (1), F90.0 (1), G40 (1), N39.4 (1).
} 


\subsection{Recruitment, Procedures and Data Collection}

Assessments were conducted using the same in-person procedures at baseline (test, T1) and the following day (re-test, T2). Sociodemographic information was self-reported, and ICD-10 diagnoses were verified against administrative systems (Table 1).

\subsection{Measures}

The Norwegian version of PAM-13 was used [14] to assess the patient groups' activation regarding their physical health. The questionnaire consists of 13 items which can be scored from (1) 'strongly disagree' to (4) 'strongly agree' or (0) 'not applicable'. The total score is calculated by dividing the raw score by the number of answered items and multiplying it by 13 . This score is further transformed through calibration tables, ranging from 0 to 100, with higher PAM scores indicating higher patient activation. Items are presented in Table 2.

Table 2. Statistics between mean scores at test and retest in both patient groups.

\begin{tabular}{|c|c|c|c|c|c|c|c|c|}
\hline & \multicolumn{4}{|c|}{ Substance Use Disorders $(N=29)$} & \multicolumn{4}{|c|}{$\begin{array}{l}\text { Schizophrenia Spectrum Disorders } \\
\qquad(N=28)\end{array}$} \\
\hline & $n$ & $\begin{array}{l}\text { Mean T1 } \\
\quad(S D)\end{array}$ & $\begin{array}{l}\text { Mean T2 } \\
\quad(S D)\end{array}$ & $p$ & $n$ & $\begin{array}{l}\text { Mean T1 } \\
\quad(S D)\end{array}$ & $\begin{array}{l}\text { Mean T2 } \\
\quad(S D)\end{array}$ & $p$ \\
\hline $\begin{array}{l}\text { 1. When all is said and done, I am the person } \\
\text { who is responsible for managing my health } \\
\text { condition }\end{array}$ & 28 & $3.79(0.42)$ & $3.64(0.68)$ & 0.180 & 27 & $3.30(0.78)$ & $3.52(0.58)$ & 0.244 \\
\hline $\begin{array}{l}\text { 2. Taking an active role in my own health care is } \\
\text { the most important factor in determining my } \\
\text { health and ability to function }\end{array}$ & 29 & $3.90(0.31)$ & $3.72(0.65)$ & 0.157 & 26 & $3.35(0.85)$ & $3.46(0.58)$ & 0.448 \\
\hline $\begin{array}{l}\text { 3. I am confident that I can take actions that will } \\
\text { help prevent or minimize some symptoms or } \\
\text { problems associated with my health condition }\end{array}$ & 28 & $3.14(0.76)$ & $3.21(0.63)$ & 0.739 & 27 & $2.93(0.78)$ & $3.00(0.73)$ & 0.642 \\
\hline $\begin{array}{l}\text { 4. I know what each of my prescribed } \\
\text { medications does }\end{array}$ & 27 & $3.89(0.32)$ & $3.67(0.62)$ & 0.058 & 26 & $3.31(0.74)$ & $3.00(0.75)$ & 0.052 \\
\hline $\begin{array}{l}\text { 5. I am confident I can tell when I need to go get } \\
\text { medical care and when I can handle a health } \\
\text { problem myself }\end{array}$ & 29 & $3.34(0.55)$ & $3.31(0.60)$ & 0.564 & 28 & $2.89(0.57)$ & $2.96(0.51)$ & 0.564 \\
\hline $\begin{array}{l}\text { 6. I am confident I can tell my health provider } \\
\text { the concerns I have even when he or she does } \\
\text { not ask }\end{array}$ & 29 & $3.34(0.81)$ & $3.34(0.77)$ & 1.000 & 28 & $2.93(0.90)$ & $3.00(0.67)$ & 0.617 \\
\hline $\begin{array}{l}\text { 7. I am confident I can follow through on the } \\
\text { medical treatment I need to do at home }\end{array}$ & 28 & $3.21(0.74)$ & $3.32(0.77)$ & 0.257 & 24 & $3.33(0.82)$ & $3.46(0.66)$ & 0.564 \\
\hline $\begin{array}{l}\text { 8. I understand the nature and causes of my } \\
\text { health condition }\end{array}$ & 29 & $3.62(0.56)$ & $3.48(0.69)$ & 0.257 & 26 & $2.96(0.87)$ & $3.04(0.66)$ & 0.557 \\
\hline $\begin{array}{l}\text { 9. I know the different medical treatment } \\
\text { options available for my health condition }\end{array}$ & 29 & $3.31(0.66)$ & $3.21(0.73)$ & 0.417 & 26 & 2.77 (1.07) & $3.08(0.80)$ & 0.153 \\
\hline $\begin{array}{l}\text { 10. I have been able to maintain the lifestyle } \\
\text { changes I have made for my health }\end{array}$ & 29 & $3.03(0.87)$ & $3.07(0.75)$ & 0.705 & 23 & $3.13(0.87)$ & $2.96(0.98)$ & 0.305 \\
\hline $\begin{array}{l}\text { 11. I know how to prevent further problems } \\
\text { with my health condition }\end{array}$ & 29 & $3.48(0.69)$ & $3.55(0.57)$ & 0.480 & 27 & $2.93(0.87)$ & $3.07(0.78)$ & 0.336 \\
\hline $\begin{array}{l}\text { 12. I am confident I can find a solution when } \\
\text { new situations or problems arise with my health } \\
\text { condition }\end{array}$ & 29 & $3.00(0.80)$ & $3.00(0.89)$ & 1.000 & 27 & $3.30(0.82)$ & $3.04(0.76)$ & 0.035 \\
\hline $\begin{array}{l}\text { 13. I am confident I can maintain lifestyles } \\
\text { changes, like diet and exercise, even during } \\
\text { times of stress }\end{array}$ & 29 & $2.62(0.86)$ & $2.55(0.95)$ & 0.739 & 27 & $2.70(0.99)$ & $2.59(0.97)$ & 0.477 \\
\hline
\end{tabular}

Individual items response options ranged from $1-4 . \mathrm{SD}=$ standard deviation; $\mathrm{T} 1$ = test; $\mathrm{T} 2$ = retest.

\subsection{Sample Size Estimation and Statistical Analyses}

Since the test-retest reliability involved two observations, a minimum of 22 participants was required to detect the value of 0.50 for the ICC [26]. To account for dropouts, 
30 participants were recruited for each group. Data was analysed using SPSS, version 22 (IBM, Armonk, New York, NY, USA). Cronbach's $\alpha$ was used to examine internal consistency. To assess test-retest reliability, ICC was calculated based on a two-way randomeffects model. The mean differences between individual scores at T1 to T2 were calculated using the Wilcoxon signed-rank test and the paired $t$-test. Statistical significance was accepted at $p<0.05$. All analyses were carried out separately for the two groups.

\section{Results}

Of the 78 patients invited to participate, 60 completed the baseline measures (T1). Subsequently, 29 SUDs and 28 schizophrenia spectrum disorders patients answered the re-test questionnaires. Data collection was performed between 2016 and 2018.

In SUDs patients, the mean item scores ranged from 2.55 (item 13) to 3.90 (item 2). There were no mean differences between T1 and T2, except for a trend in item $4(p=0.058$, Table 2). ICC was $r=0.86$, and Cronbach's $\alpha$ was 0.75 and 0.84 at T1 and T2, respectively (Table 3). In schizophrenia spectrum disorders patients, the mean item scores ranged from 2.59 (item 13) to 3.52 (item 1). There were no mean differences between T1 and T2, except for item $12(p<0.05$, Table 2$)$ and a trend in item $4(p=0.052$, Table 2). ICC was $r=0.93$, and Cronbach's $\alpha$ was 0.87 and 0.81 at T1 and T2, respectively (Table 3).

Table 3. Reliability and internal consistency statistics.

\begin{tabular}{ccc}
\hline & $\begin{array}{c}\text { Substance Use Disorders } \\
(\boldsymbol{N}=\mathbf{2 9 )}\end{array}$ & $\begin{array}{c}\text { Schizophrenia Spectrum } \\
\text { Disorders }(\boldsymbol{N}=\mathbf{2 8})\end{array}$ \\
\hline Cronbach's alpha T1 & 0.75 & 0.87 \\
Cronbach's alpha T2 & 0.84 & 0.81 \\
Total mean $(S D)$ T1 & $69.8(11.6)$ & $59.5(15.0)$ \\
Total mean $(S D)$ T2 & $67.6(14.8)$ & $60.2(13.4)$ \\
ICC $(95 \% C I)$ & $0.86(0.77-0.93)$ & $0.93(0.86-0.97)$ \\
\hline
\end{tabular}

$\overline{\mathrm{SD}}$ = standard deviation; $\mathrm{T} 1$ = test; $\mathrm{T} 2$ = retest; $\mathrm{ICC}$ = intraclass correlation coefficient; $\mathrm{CI}$ = confidence interval.

\section{Discussion}

Our findings show that, for SUDs patients and schizophrenia spectrum disorders patients, PAM-13 possesses good internal consistency, with Cronbach's $\alpha$ values ranging between 0.75 and 0.87 at both assessments [27]. The Cronbach's $\alpha$ values are comparable to those obtained in patient groups with chronic somatic illnesses [13,15-17,28], those undergoing surgery [12] and those with non-severe mental disorders [14].

Our ICC scores imply good test-retest reliability $(\geq 0.70)[27,29]$ in both patient groups, reflected by only item 12 being significantly different at re-test among schizophrenia spectrum disorders patients, and a trend towards a difference for item 4 in both patient groups. To our knowledge, only one previous study investigated the test-retest reliability of PAM-13 in a mental health population [14]. As that study did not include patients with schizophrenia spectrum disorders or SUDs, our findings add to the limited information regarding the test-retest reliability of PAM-13 in a mental health setting. The ICC score for the patients with schizophrenia spectrum disorders was higher than what has been observed previously in outpatients with less severe mental disorders at one-month followups [14], patients undergoing spine surgery at one-week follow-ups [12] or those with chronic diseases at two-week follow-ups [17]. ICC scores for SUDs patients were, however, comparable to the aforementioned studies.

It is interesting that the poor physical health, which has been observed previously in both SUDs and schizophrenia spectrum disorders patients [30-34], is also reflected in PAM-13, as both groups scored lowest on item 13, suggesting poor confidence in their abilities to maintain lifestyle changes regarding diet and exercise. As shown in this study, the measurement of patient activation may be helpful in clinical research, as well as a useful tool to identify patients in need of increased support regarding their own health 
management, which is often the case in these patient groups. Thus, PAM- 13 can potentially contribute to improved patient involvement in their own health management.

The mean activation scores for our SUDs patients are comparable to what has previously been found in other SUDs patients [25], while the mean activation scores reported in mental disorder patients seem more spread, with our values of $\sim 60$ lying above most other reported values [14,20,23,24] but also lower than others [25].

Patient groups within mental health settings often struggle with several severe physical health challenges [30-34]. Thus, a strength of the current study is the use of PAM-13, the gold standard for assessing patient health activation. This study in turn, since it has evaluated the reliability of PAM-13 in a new setting, further expands the utilization of PAM-13 to understand the physical health challenges of these patient groups. A possible limitation to this study is the inclusion of patients from only two centres, which may limit the possibility of generalizing our findings. Another limitation could be the short test-re-test interval. However, as both patient groups are prone to relapse, having a long test-re-test interval would therefore not be ideal; nevertheless, it may be useful to consider replicating this study with a longer time interval. When planning reliability studies, it is recommended to have an a priori calculation of sample size $[27,35]$. Even though a sample size estimate for ICC was done a priori, there were no power calculation for internal consistency. According to methodological studies, a sample size of a minimum of 30 participants is an adequate estimator of the population coefficient alpha [36] as well as for ICC analysis [26]. Even though the aim was to include 30 participants in each sample, patients were lost to re-retest. This left less than 30 participants with complete test-retest data. This limitation must be considered when interpreting the results and planning future studies. To advance future research it is recommended to have an a priori calculation of sample size based on Cronbach's alpha taking in consideration dropouts at retest. Further studies assessing principal component analysis, in a large sample, are recommended. Until this is done, the present study is an important step paving the way towards measuring patient activation and gaining knowledge regarding the reliability of PAM-13 among patients in addiction and mental health settings.

\section{Conclusions}

PAM-13 shows good internal consistency and test-retest reliability in adults with SUDs and schizophrenia spectrum disorders and may be helpful in a variety of clinical research settings, including inpatient and outpatient populations. For health care providers, PAM13 can potentially be useful in identifying areas where different patients need increased support regarding their own health management, potentially resulting in less relapse and better activation.

Author Contributions: Conceptualization, K.M., M.N. and M.L.L.-C.; Methodology and Validation, K.M., M.N. and M.L.L.-C.; Formal Analysis, K.M., M.N. and M.L.L.-C.; Investigation, K.M., M.N., M.L.L.-C. and M.F.B.; Writing-Original Draft Preparation, K.M., M.N., M.L.L.-C. and R.W.G.; Writing-Review \& Editing, K.M., M.N., M.L.L.-C., R.W.G., M.F.B., I.C.G., S.K.R., E.V.-K. and J.H.; Supervision, M.L.L.-C., J.H., E.V.-K. and R.W.G.; Project Administration, J.H., E.V.-K. and R.W.G.; Funding Acquisition, J.H., E.V.-K. and R.W.G. All authors have read and agreed to the published version of the manuscript.

Funding: This work was supported by grants from the Norwegian Directorate of Health, the Liaison Committee for Education, Research and Innovation in Central Norway (No: 90063100/2015 and 90327500/2018), the Faculty of Medicine and Health Sciences of the Norwegian University of Science and Technology (NTNU), the Research Departments of St. Olav University Hospital and the joint research council between St. Olav University Hospital and the Faculty of Medicine and Health Sciences (FFU). They had no role in the study's design, data collection, analysis, writing or in the decision to submit the article for publication.

Institutional Review Board Statement: The combination of data from the two aforementioned studies to form this paper was approved by the Regional Committee for Medical and Health Re- 
search Ethics in Mid-Norway (No.2016/1882, approved 21 May 2019) and South-East Norway (No.2015/1611, approved 27 May2019).

Informed Consent Statement: Data collection was conducted in accordance with the Helsinki Declaration, and informed consent forms were signed prior to data collection.

Data Availability Statement: The data presented in this study are available from the corresponding author upon reasonable request. The data are not publicly available due to ethical reasons.

Acknowledgments: We are grateful to all the patients who volunteered to take part at the Blue Cross Lade Addiction Treatment Centre, Trondheim, Norway. We are also thankful to the participants in the LEXUS study at the Exercise Training Clinic at Østmarka Psychiatric Hospital, Trondheim, Norway. We would also like to thank Trond O. Aamo and Olav Spigset for their contribution with proof reading of this article. We thank the Liaison Committee for Education, Research and Innovation in Central Norway; Blue Cross Lade Addiction Treatment Centre, Trondheim, Norway; Department of Østmarka, Division of Mental Health Care, St. Olavs Hospital, Trondheim University Hospital, Trondheim, Norway and Department of Research and Development, Division of Mental Health Care, St. Olavs Hospital, Trondheim University Hospital, Trondheim, Norway for administratively supporting this work.

Conflicts of Interest: The authors declare no conflict of interest. The funders had no role in the design of the study; in the collection, analyses, or interpretation of data; in the writing of the manuscript, or in the decision to publish the results.

\section{References}

1. Vossius, C.; Testad, I.; Skjaeveland, R.; Nesvag, S. The use and costs of health and social services in patients with longstanding substance abuse. BMC Health Serv. Res. 2013, 13, 185. [CrossRef]

2. Jin, H.; Mosweu, I. The Societal Cost of Schizophrenia: A Systematic Review. Pharmacoeconomics 2017, 35, 25-42. [CrossRef]

3. Brorson, H.H.; Arnevik, E.A.; Rand-Hendriksen, K.; Duckert, F. Drop-out from addiction treatment: A systematic review of risk factors. Clin. Psychol. Rev. 2013, 33, 1010-1024. [CrossRef]

4. Gunatilake, S.; Ananth, J.; Parameswaran, S.; Brown, S.; Silva, W. Rehabilitation of schizophrenic patients. Curr. Pharm. Des. 2004, 10, 2277-2288. [CrossRef]

5. Davoli, M.; Bargagli, A.M.; Perucci, C.A.; Schifano, P.; Belleudi, V.; Hickman, M.; Salamina, G.; Diecidue, R.; Vigna-Taglianti, F.; Faggiano, F. Risk of fatal overdose during and after specialist drug treatment: The VEdeTTE study, a national multi-site prospective cohort study. Addiction 2007, 102, 1954-1959. [CrossRef]

6. Nordentoft, M.; Wahlbeck, K.; Hallgren, J.; Westman, J.; Osby, U.; Alinaghizadeh, H.; Gissler, M.; Laursen, T.M. Excess mortality, causes of death and life expectancy in 270,770 patients with recent onset of mental disorders in Denmark, Finland and Sweden. PLOS ONE 2013, 8, e55176. [CrossRef]

7. Hibbard, J.H.; Stockard, J.; Mahoney, E.R.; Tusler, M. Development of the Patient Activation Measure (PAM): Conceptualizing and measuring activation in patients and consumers. Health Serv. Res. 2004, 39, 1005-1026. [CrossRef] [PubMed]

8. Hibbard, J.H.; Greene, J. What the evidence shows about patient activation: Better health outcomes and care experiences; fewer data on costs. Health Aff. 2013, 32, 207-214. [CrossRef]

9. Kinney, R.L.; Lemon, S.C.; Person, S.D.; Pagoto, S.L.; Saczynski, J.S. The association between patient activation and medication adherence, hospitalization, and emergency room utilization in patients with chronic illnesses: A systematic review. Patient Educ. Couns. 2015, 98, 545-552. [CrossRef]

10. Hibbard, J.H.; Mahoney, E.R.; Stockard, J.; Tusler, M. Development and testing of a short form of the patient activation measure. Health Serv. Res. 2005, 40, 1918-1930. [CrossRef]

11. Begum, N.; Donald, M.; Ozolins, I.Z.; Dower, J. Hospital admissions, emergency department utilisation and patient activation for self-management among people with diabetes. Diabetes Res. Clin. Pract. 2011, 93, 260-267. [CrossRef] [PubMed]

12. Skolasky, R.L.; Mackenzie, E.J.; Riley, L.H., 3rd; Wegener, S.T. Psychometric properties of the Patient Activation Measure among individuals presenting for elective lumbar spine surgery. Qual. Life Res. 2009, 18, 1357-1366. [CrossRef] [PubMed]

13. Rademakers, J.; Nijman, J.; van der Hoek, L.; Heijmans, M.; Rijken, M. Measuring patient activation in The Netherlands: Translation and validation of the American short form Patient Activation Measure (PAM13). BMC Public Health 2012, $12,577$. [CrossRef] [PubMed]

14. Moljord, I.E.; Lara-Cabrera, M.L.; Perestelo-Perez, L.; Rivero-Santana, A.; Eriksen, L.; Linaker, O.M. Psychometric properties of the Patient Activation Measure-13 among out-patients waiting for mental health treatment: A validation study in Norway. Patient Educ. Couns. 2015, 98, 1410-1417. [CrossRef] [PubMed]

15. Bomba, F.; Markwart, H.; Muhlan, H.; Menrath, I.; Ernst, G.; Thyen, U.; Schmidt, S. Adaptation and validation of the German Patient Activation Measure for adolescents with chronic conditions in transitional care: PAM((R)) 13 for Adolescents. Res. Nurs. Health 2018, 41, 78-87. [CrossRef] [PubMed] 
16. Kosar, C.; Besen, D.B. Adaptation of a patient activation measure (PAM) into Turkish: Reliability and validity test. Afr. Health Sci. 2019, 19, 1811-1820. [CrossRef] [PubMed]

17. Cunha, C.M.; da Cunha, D.; Manzato, R.O.; Nepomuceno, E.; da Silva, D.; Dantas, R.A.S. Validation of the Brazilian Version of the Patient Activation Measure 13. J. Nurs. Meas. 2019, 27, 97-113. [CrossRef] [PubMed]

18. Hellstrom, A.; Kassaye Tessma, M.; Flink, M.; Dahlgren, A.; Schildmeijer, K.; Ekstedt, M. Validation of the patient activation measure in patients at discharge from hospitals and at distance from hospital care in Sweden. BMC Public Health 2019, $19,1701$. [CrossRef]

19. Bahrom, N.H.; Ramli, A.; Isa, M.; Baharudin, N.; Badlishah-Sham, S.; Mohamed-Yassin, M.; Abdul-Hamid, H. Validity and reliability of the Patient Activation Measure ${ }^{(}(\mathrm{PAM} ®)-13$ Malay version among patients with Metabolic Syndrome in primary care. Malays. Fam. Phys. 2020, 15, 22.

20. Kukla, M.; Salyers, M.P.; Lysaker, P.H. Levels of patient activation among adults with schizophrenia: Associations with hope, symptoms, medication adherence, and recovery attitudes. J. Nerv. Ment. Dis. 2013, 201, 339-344. [CrossRef]

21. Salyers, M.P.; Matthias, M.S.; Spann, C.L.; Lydick, J.M.; Rollins, A.L.; Frankel, R.M. The role of patient activation in psychiatric visits. Psychiatr. Serv. 2009, 60, 1535-1539. [CrossRef]

22. Moljord, I.; Lara-Cabrera, M.; Salvesen, Ø.; Rise, M.; Bjørgen, D.; Antonsen, D.; Olsø, T.; Evensen, G.; Gudde, C.; Linaker, O. Twelve months effect of self-referral to inpatient treatment on patient activation, recovery, symptoms and functioning: A randomized controlled study. Patient Educ. Couns. 2017, 100, 1144-1152. [CrossRef] [PubMed]

23. Lara-Cabrera, M.L.; Salvesen, Ø.; Nesset, M.B.; De las Cuevas, C.; Iversen, V.C.; Gråwe, R.W. The effect of a brief educational programme added to mental health treatment to improve patient activation: A randomized controlled trial in community mental health centres. Patient Educ. Couns. 2016, 99, 760-768. [CrossRef] [PubMed]

24. Druss, B.G.; Singh, M.; von Esenwein, S.A.; Glick, G.E.; Tapscott, S.; Tucker, S.J.; Lally, C.A.; Sterling, E.W. Peer-Led SelfManagement of General Medical Conditions for Patients With Serious Mental Illnesses: A Randomized Trial. Psychiatr. Serv. 2018, 69, 529-535. [CrossRef] [PubMed]

25. Young, J.T.; Heffernan, E.; Borschmann, R.; Ogloff, J.R.P.; Spittal, M.J.; Kouyoumdjian, F.G.; Preen, D.B.; Butler, A.; Brophy, L.; Crilly, J.; et al. Dual diagnosis of mental illness and substance use disorder and injury in adults recently released from prison: A prospective cohort study. Lancet Public Health 2018, 3, e237-e248. [CrossRef]

26. Bujang, M.A.; Baharum, N. A simplified guide to determination of sample size requirements for estimating the value of intraclass correlation coefficient: A review. J. Orofac Sci. 2017, 12, 1-11.

27. Mokkink, L.B.; Prinsen, C.; Patrick, D.L.; Alonso, J.; Bouter, L.M.; de Vet, H.; Terwee, C.B.; Mokkink, L. COSMIN methodology for systematic reviews of patient-reported outcome measures (PROMs). User Man. 2018, 78, 1.

28. Kim, S.; Kim, E.; Ryu, E. Illness Perceptions, Self-Care Management, and Clinical Outcomes According to Age-Group in Korean Hemodialysis Patients. Int. J. Environ. Res. Public Health 2019, 16, 4459. [CrossRef]

29. Keszei, A.P.; Novak, M.; Streiner, D.L. Introduction to health measurement scales. J. Psychosom. Res. 2010, 68, 319-323. [CrossRef]

30. Flemmen, G.; Wang, E. Impaired Aerobic Endurance and Muscular Strength in Substance Use Disorder Patients: Implications for Health and Premature Death. Medicine 2015, 94, e1914. [CrossRef]

31. Mosti, M.P.; Flemmen, G.; Hoff, J.; Stunes, A.K.; Syversen, U.; Wang, E. Impaired skeletal health and neuromuscular function among amphetamine users in clinical treatment. Osteoporos. Int. 2016, 27, 1003-1010. [CrossRef]

32. Brobakken, M.F.; Nygard, M.; Taylor, J.L.; Guzey, I.C.; Morken, G.; Reitan, S.K.; Heggelund, J.; Vedul-Kjelsaas, E.; Wang, E. A comprehensive cardiovascular disease risk profile in patients with schizophrenia. Scand. J. Med. Sci. Sports 2019. [CrossRef] [PubMed]

33. Heggelund, J.; Hoff, J.; Helgerud, J.; Nilsberg, G.E.; Morken, G. Reduced peak oxygen uptake and implications for cardiovascular health and quality of life in patients with schizophrenia. BMC Psychiatry 2011, 11, 188. [CrossRef] [PubMed]

34. Nygard, M.; Brobakken, M.F.; Roel, R.B.; Taylor, J.L.; Reitan, S.K.; Guzey, I.C.; Morken, G.; Vedul-Kjelsas, E.; Wang, E.; Heggelund, J. Patients with schizophrenia have impaired muscle force-generating capacity and functional performance. Scand. J. Med. Sci. Sports 2019, 29, 1968-1979. [CrossRef] [PubMed]

35. Bonett, D.G. Sample size requirements for testing and estimating coefficient alpha. J. Educ. Behav. Stat. 2002, 27, 335-340. [CrossRef]

36. Yurdugül, H. Minimum sample size for Cronbach's coefficient alpha: A Monte-Carlo study. Hacet. Üniversitesi Ĕ̆itim Fakültesi Derg. 2008, 35, 1-9. 